\title{
Identification of candidate risk gene variations by whole-genome sequence analysis of four rat strains commonly used in inflammation research
}

\author{
Liselotte Bäckdahl1 ${ }^{1,3^{*}}$, Diana Ekman ${ }^{1}$, Maja Jagodic ${ }^{2}$, Tomas Olsson² and Rikard Holmdahl ${ }^{1}$
}

\begin{abstract}
Background: The DA rat strain is particularly susceptible to the induction of a number of chronic inflammatory diseases, such as models for rheumatoid arthritis and multiple sclerosis. Here we sequenced the genomes of two DA sub-strains and two disease resistant strains, E3 and PVG, previously used together with DA strains in genetically segregating crosses.

Results: The data uncovers genomic variations, such as single nucleotide variations (SNVs) and copy number variations that underlie phenotypic differences between the strains. Comparisons of regional differences between the two DA sub-strains identified 8 genomic regions that discriminate between the strains that together cover $38 \mathrm{Mbp}$ and harbor 302 genes. We analyzed 10 fine-mapped quantitative trait loci and our data implicate strong candidates for genetic variations that mediate their effects. For example we could identify a single SNV candidate in a regulatory region of the gene $1 / 21 r$, which has been associated to differential expression in both rats and human MS patients. In the APLEC complex we identified two SNVs in a highly conserved region, which could affect the regulation of all APLEC encoded genes and explain the polygenic differential expression seen in the complex. Furthermore, the non-synonymous SNV modifying aa153 of the Ncf1 protein was confirmed as the sole causative factor.
\end{abstract}

Conclusion: This complete map of genetic differences between the most commonly used rat strains in inflammation research constitutes an important reference in understanding how genetic variations contribute to the traits of importance for inflammatory diseases.

Keywords: Rat genome, Whole-genome sequencing, QTL, Rheumatoid arthritis, Multiple sclerosis, Disease-associated SNVS

\section{Background}

The laboratory rat is a widely used model organism for studying both basic mechanisms of physiology, and disease models of human diseases. Inbred rat strains and genetically segregating crosses are important tools in functionally proving disease mechanisms and represents a controlled setting where molecular interactions between different genetic factors as well as environmental factors can be tested [1].

\footnotetext{
* Correspondence: liselotte.backdahl@ki.se

'Medical Inflammation Research, Department of Medical Biochemistry and Biophysics, Karolinska Institutet, Stockholm, Sweden

${ }^{3}$ Unit of Medical inflammatory disease, Department of Medical Biochemistry, Karolinska Institutet, Scheeles väg 2, B2 plan 4, 17177 Stockholm, Sweden Full list of author information is available at the end of the article
}

There are many common characteristics between chronic inflammatory diseases like Rheumatoid Arthritis (RA) [2], and Multiple Sclerosis (MS) [3]: these diseases are both consequences of dys-regulated immune responses that has initially been triggered by a combination of genetic and environmental factors. Peripheral joints in RA and myelin sheets in the central nervous system in MS are the sites of persistent inflammation that leads to tissue destruction. The most highly associated genetic region for the majority of these diseases is the Major Histocompatibility Complex (MHC) and especially HLA II genes [4]. Despite recent progress in identifying loci that associate with complex diseases in human [5], the identification of the causative genetic polymorphisms, (both within and outside $\mathrm{MHC}$ ), and the understanding of their pathophysiological roles, still represents a significant

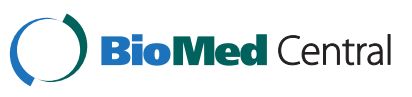


challenge. The complexity of chronic inflammatory diseases lies not only in intricate interactions between genes and environment, but also in elaborate genetic phenomena such as gene-gene interactions, synergistic effects and epigenetic mechanisms.

Animal models provide a means to control environmental factors and manipulate the genetic contribution. Although the disease causing polymorphisms are not likely to be identical with humans we expect the associated pathophysiologic pathways to be conserved. Using animal models could be a way to reveal their genetic complexity. In addition, the environmental exposure can be controlled and experimental manipulations are possible to perform. One other benefit of using animal models for genetic research is the possibility to selectively modify the genome e.g. producing congenic, knock-out or transgenic strains and linkage mapping.

DA rats are remarkably susceptible to a number of autoimmune diseases; experimental arthritis induced with collagen [6] or hydrocarbons such as mineral oil [7] or pristane oil [8], experimental autoimmune encephalomyelitis [9], experimental allergic neuritis [10], experimental allergic uveitis [11], and experimental autoimmune thyroiditis [12]. Also among other inbred rat strains, the DA rat is the most prone to develop inflammation (Figure 1). This disease susceptibility is mediated by both MHC and non-MHC genes. It is the only strain susceptible to oilinduced arthritis and other arthritis inducers provoke very severe disease in DA compared to other susceptible strains. It has been shown that DA rats from different colonies differ in disease susceptibility as well as contain distinct regions of genetic differences [13], therefore we decided to sequence 2 sub-strains of DA; DA/OlaHsd and DA/hanKini ( here abbreviated as DA/O and DA/K).

Genetic linkage studies using F2 animals from an inter-cross between DA and different disease resistant strains have identified about 50 quantitative trait loci
(QTLs) associated with susceptibility to inflammatory diseases. These QTLs together cover approximately 20 genomic regions in the DA rat that have been confirmed in more than one F2 inter-cross (Figure 2). The first F2 cross that used DA as the inflammation susceptible strain was a DA/K x E3 cross in Pristane induced arthritis (PIA), that identified QTLs on chromosome 6, 4, 12, and 14 [8]. Three more arthritis mapping studies and two in EAE utilizing DA/K x E3 F2 inter-crosses could verify the first four QTLs and identified new QTLs on chromosome 20 (MHC region), 10, 1, and 18 [15-19]. Dahlman et al. used a DA/K x ACI F2 cross in EAE to identify QTLs on chr 4, 7, 10, 12, 13, 15, 18, and X [20]. The QTLs on chr 4,10,12, 15 were later confirmed in DA/K x PVG.1AV1 advanced intercross line (AIL) [21-26]. In 1998 two arthritis QTLs were identified in LEW.1AV1x PVG.1AV1 on chr 4 and 10 that later were replicated in a DA/K x PVG.1AV1 F2 [27,28]. In 2003 a LEW.1AV1 x PVG.1AV1 F2 cross identified two new QTLs on chromosome 1 and 17 [29] that were replicated in two DA/K $\mathrm{x}$ PVG.1AV1 AIL populations [30-33]. The PVG.1AV1 is a congenic strain sharing the $\mathrm{MHC}$ region with $\mathrm{DA}$, but is still resistant or develops extremely mild disease in response to most inflammation inducers. The E3 strain is an independent inbred rat strain that is highly resistant to most inflammatory diseases but which tends to develop obesitas and has a coagulation defect [34]. Aiming to identify genomic regions that differ between disease susceptible and resistant strains, DA/O, DA/K, E3/han and PVG/ 1AV1.Kini were selected for sequencing.

Since the main purpose of this sequencing effort has been to create a tool to be used in all genetic studies of the inflammatory rat we have also selected 10 quantitative trait loci (QTLs) that are $\sim 1 \mathrm{Mb}$ in size, to dissect and report all the variations in the interval. Main emphasis is put on non-synonymous SNVs (nsSNVs), synonymous SNVs (sSNVs), SNVs in UTRs, splice-site SNVs and SNVs

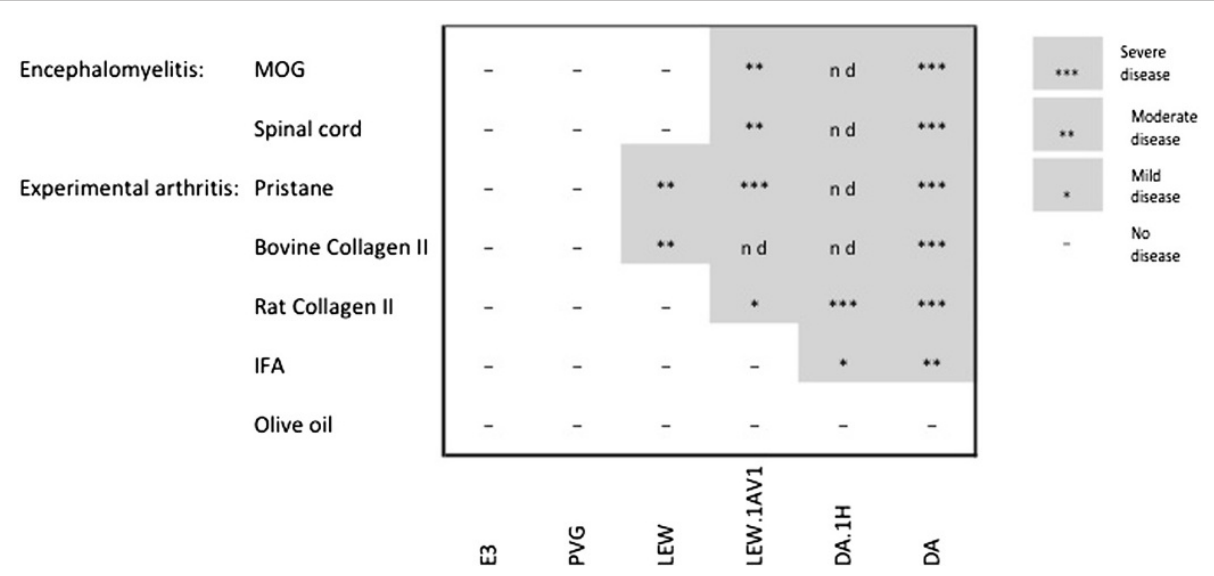

Figure 1 The genomic influence on disease susceptibility. The influence of genomic variations on the development of inflammatory disease by different genomes and MHC haplotypes. The illustration is an adaptation from [14]. 


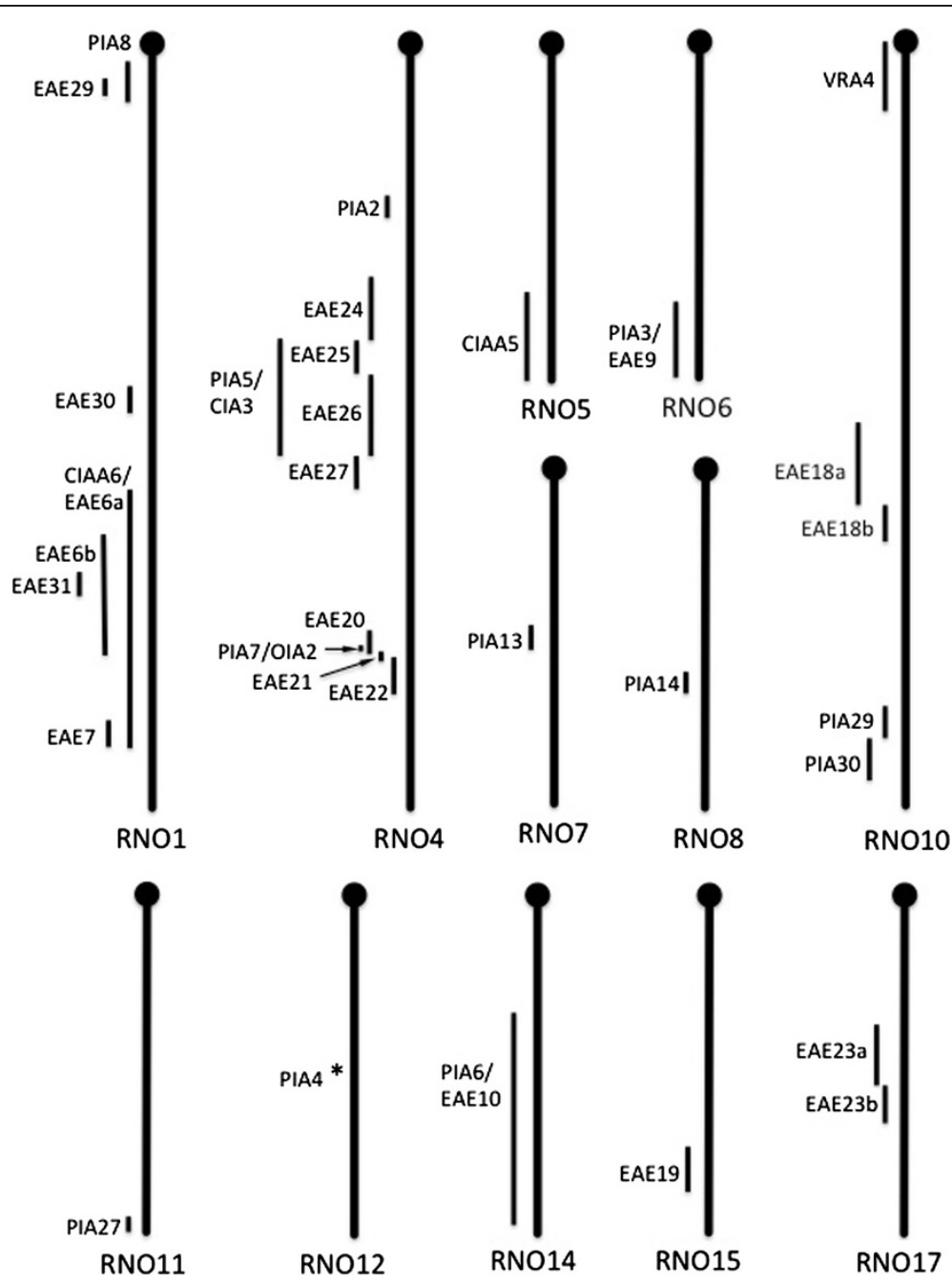

Figure 2 Arthritis and EAE regulating QTLs in the DA genome. Chromosome maps illustrating the genomic intervals of inflammatory disease regulating QTLs in the DA rat genome associated with mapping studies in DA/E3 or DA/PVG crosses and congenic strain.

found in regions of high conservation between different species (PhastCons9way). The new SNVs that are identified will have to be analyzed in more detail and assessed experimentally. However, they represent an entry point for functional validation of candidate molecular genetic mechanisms underlying established QTLs.

The identified QTLs that segregate between DA and E3/ PVG signify regions of regulatory importance in the development of chronic inflammatory disease. Identifying the underlying factors within these disease-regulating regions would give important clues also for the diseases in human. The complete genomic sequence of the DA strain and the disease resistant strains E3 and PVG comprise invaluable resources in the study of the polygenic nature of complex diseases such as chronic inflammatory diseases.

\section{Results and discussion}

\section{Sequencing and variation calling}

The four genomes DA/OlaHsd (DA/O), DA/hanKini (DA/K), E3/han (E3) and PVG/1AV1.Kini (PVG) were sequenced in three separate runs using the $\mathrm{SOLiD}^{\text {tw }}$ technology. Aiming to also identify structural variations we made three Mate-pair libraries with different insert sizes; $1 \mathrm{~kb}$, $2 \mathrm{~kb}$, and $4 \mathrm{~kb}$ as well as one paired end library. The reads were then mapped to the BN (RGSC3.4) reference genome with BWA [35]. This resulted in median coverage of 1822X (DA/O: 18X, DA/K 22X, E3 19X, PVG 19X) and enabled us to cover $>99 \%$ of the BN reference sequence with at least one read for all four genomes (Additional file 1).

SNVs and short indels were identified using a strategy developed by Guryev et al [36]. To call a variant we required a minimum coverage of three reads and at least 
$75 \%$ of the reads had to support the non-reference allele. This predicted about 5.3 million SNVs and 0.4 million short indels for all four genomes combined.

By comparing our SNVs with the genotypes from the STAR consortium [37] we estimated the sensitivity to be about $96.8-97.8 \%$. In addition, we sequenced 100 regions (300-500 bp in size) with capillary sequencing. Of the 178 SNVs identified by capillary sequencing 171 SNVs were also identified by the SOLiD sequencing, whereas two of the undetected SNVs were missed because less than $75 \%$ of the reads carried the non-reference allele. 33 of the tested SNVs were in the coding sequence of a gene and all these variants was identified in the SOLiD SNVs. Four of the undetected SNVs are in the hyperpolymorphic MHC region on chromosome 20. Further, no false positives were identified in these sequences.

\section{Variation analysis for the four genomes}

\section{SNVs}

Each genome has about 3 million SNVs and 0.3-0.36 million indels compared to the $\mathrm{BN}$ reference. Approximately $70 \%$ of all SNVs are outside ref-seq annotated gene regions. About $1 \%$ of the SNVs are located in coding regions, and $21 \%$ of the SNVs in coding regions are non-synonymous (Table 1 ).

Pair-wise comparison identified that more than $98 \%$ of the high-quality ( $\geq 8 \mathrm{X}$ coverage) SNVs in DA/O are shared with the closely related DA/K. Analyzing the SNP distribution of the strains showed that about $14 \%$ of all SNVs identified are unique to DA/O and DA/K, compared to BN, E3 and PVG (Figure 3). Further, 29\% of the identified SNVs are shared by all four genomes and differ only from the $\mathrm{BN}$ reference sequence. A more detailed distribution of the SNVs can be found in Table 2.

\section{Stop codons}

Each strain has between 70-79 SNVs that results in a predicted premature stop codon (Additional file 2). This affects a total of 131 genes, where about 60\% are uncharacterized genes or olfactory and vomeronasal receptors. Further, in 32 of these genes the stop codon was predicted in an alternatively transcribed gene, and not affecting all annotated

Table 1 SNVs and short indels ( $<10 \mathrm{bp}$ ) compared to the BN reference

\begin{tabular}{|c|c|c|c|c|c|c|}
\hline Strain & SNVs & $\begin{array}{c}\text { SNVs in } \\
\text { gene regions } \\
( \pm \mathrm{kb})\end{array}$ & $\begin{array}{l}\text { SNVs in } \\
\text { cds }\end{array}$ & $\begin{array}{l}\text { NS coding } \\
\text { SNVs }\end{array}$ & $\begin{array}{l}\text { Short } \\
\text { indels }\end{array}$ & $\begin{array}{l}\text { Indels } \\
\text { in cds }\end{array}$ \\
\hline $\mathrm{DA} / O$ & $3.02 \mathrm{M}$ & $0.87 \mathrm{M}$ & 30440 & 6639 & $0.34 \mathrm{M}$ & 1206 \\
\hline $\mathrm{DA} / \mathrm{K}$ & $2.94 \mathrm{M}$ & $0.86 \mathrm{M}$ & 31130 & 6706 & $0.30 \mathrm{M}$ & 1243 \\
\hline E3 & $3.09 \mathrm{M}$ & $0.91 \mathrm{M}$ & 31426 & 6432 & $0.36 \mathrm{M}$ & 1294 \\
\hline PVG & $2.99 \mathrm{M}$ & $0.86 \mathrm{M}$ & 31318 & 6432 & $0.30 \mathrm{M}$ & 1241 \\
\hline
\end{tabular}

Cds = Coding sequence.

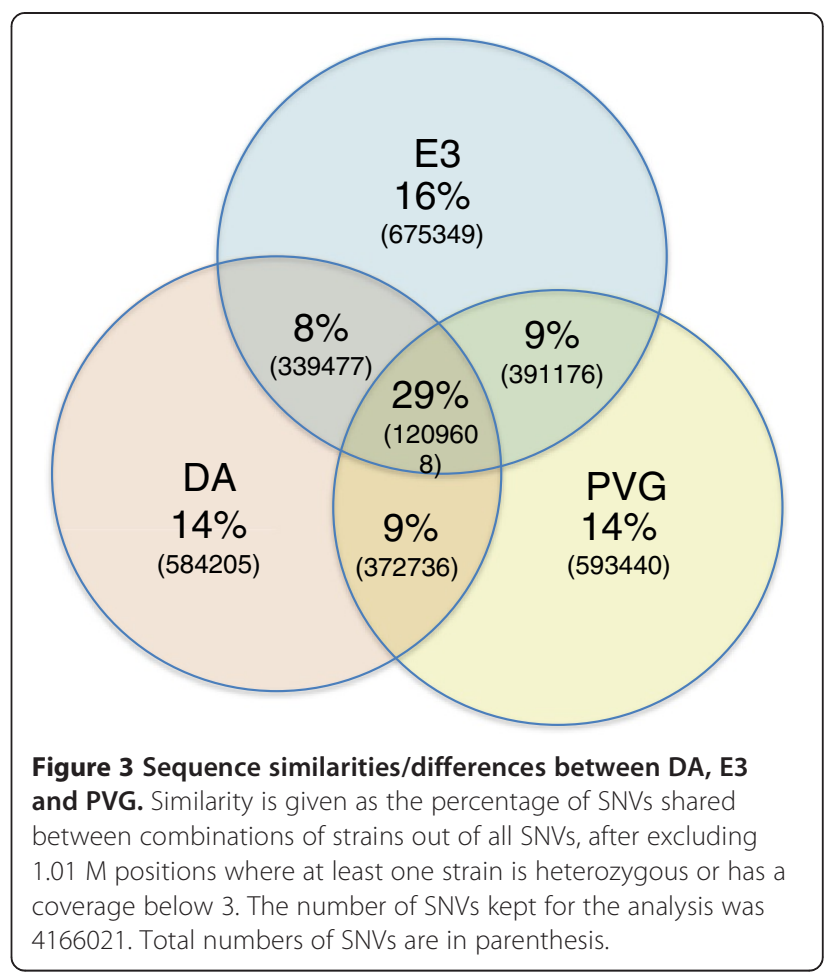

transcripts from the gene. 33 of the stop introducing SNVs were found in all 4 strains, whereas 56 are only present in one strain, with 23 unique for DA, 14 for PVG and 19 for E3. Furthermore, there is one stop gaining unique to the $\mathrm{DA} / \mathrm{K}$ strain in the Grb14 gene.

\section{Structural variants}

Next, we searched for structural variants between the strains. We detected 45 duplications in the range of 0.4$149 \mathrm{kbp}$, and 96 deletions between 1.8-134 kbp between DA/O and E3 (Additional file 3). Deletions were predicted to affect 96 genes in DA/O and 47 genes in E3. Fewer genes (42) were affected by deletions in DA/K compared to PVG and 36 genes in PVG compared to DA. The large number of gene deletions in DA compared to E3 is to a large extent due to deletions on chromosome 7 and 15, most of which are also deleted in PVG.

\section{Correlating SNVs in different genomic features with differential expression and alternative splicing}

Aiming to dissect the influence from SNVs occurring in different coding or transcript regulatory sequences such as splice-sites or UTRs, on differential expression and splicing, we compared the occurrence of SNVs within a certain gene with the expression of that gene. Intragenic SNVs were compared to a set of differentially expressed or alternatively spliced genes from a study by Gillett et al. [38]. In this study differential expression and alternative splicing was analyzed in RNA from lymph node cells from 
Table 2 A summary of identified high-quality SNVs (coverage $>8$ ) between, DA/K and DA/O, DA/K and PVG and DA/O and $\mathrm{E3}$ and the distribution of SNVs across genomic features

\begin{tabular}{|c|c|c|c|c|c|}
\hline & $\mathrm{DA} / \mathrm{O} \neq \mathrm{DA} / \mathrm{K}$ & $\mathrm{DA} / \mathrm{O} \neq \mathrm{E} 3$ & $\mathrm{DA} / \mathrm{K} \neq \mathrm{PVG}$ & $\mathrm{DA} / \mathrm{O}+/ \mathrm{K} \neq \mathrm{E} 3=\mathrm{PVG}$ & $\mathrm{BN} \neq \mathrm{DA} / \mathrm{O}+/ \mathrm{K}+\mathrm{E} 3+\mathrm{PVG}$ \\
\hline Stop gained & 1 & 48 & 37 & 22 & 10 \\
\hline Stop lost & 0 & 3 & 2 & 1 & 2 \\
\hline Non-synonymous & 108 & 3688 & 3374 & 1628 & 1437 \\
\hline Synonymous & 224 & 7398 & 7546 & 3193 & 2770 \\
\hline Essential splice site & 1 & 41 & 36 & 23 & 20 \\
\hline splice site & 21 & 1013 & 973 & 451 & 401 \\
\hline 5'prime UTR & 21 & 644 & 692 & 270 & 231 \\
\hline 3' prime UTR & 113 & 4761 & 4481 & 2029 & 1860 \\
\hline Intronic & 13949 & 436591 & 347893 & 180040 & 171296 \\
\hline Uppstream & 1322 & 49342 & 40423 & 19954 & 18148 \\
\hline Downstream & 1215 & 41414 & 34053 & 16472 & 14919 \\
\hline
\end{tabular}

$\mathrm{DA} / \mathrm{K}$ and PVG rats 7 days after induction of EAE. They detected 13 genes with convincing evidence of differential splicing between DA and PVG, of which three (Prex1, Itpr2 and Nab1) have predicted splice site variants that are unique to PVG. Further, 11 had coding SNVs. Naturally; it needs to be further investigated if these are the variants that lead to the altered splicing.

To assess the correlation between differential expression or splicing and SNVs on a larger scale, we looked for SNVs in coding or UTR regions as well as in splice sites in all genes with differential expression or splicing between DA/K and PVG in the Gillett et al. study and compared this with how often such SNVs occur in genes that were not differentially expressed or spliced. There was a significant enrichment of genes with SNVs in UTRs and coding sequences among the genes that displayed differential expression compared to genes that did not (Figure 4a). Due to the multiple probe design of the Affymetrix arrays, the coding SNVs should not influence the actual hybridization to the array and thus the difference should be reflecting the biology [39]. Similarly, there was an enrichment of genes with SNVs in splice sites, UTRs and coding regions in alternatively spliced genes compared to the genes where no alternative splicing was detected (Figure $4 \mathrm{~b}$ ). This suggests that coding SNVs as well as SNVs in UTRs and in splice sites are more frequent in genes that display differential expression or alternative splicing. However, there are still many genes without the variants that are differentially regulated. Hence, the absence of such variants cannot be used to exclude a gene as a candidate. In addition, there are additional types of genomic variations, such as larger structural variants like partial and whole gene duplications, which also need to be analyzed, since they can have a major impact on gene expression and splicing [40].
Pairwise comparison of disease susceptible and resistant genomes

\section{Comparing two DA sub-strains}

There are more than 1 million of the identified SNVs between DA and E3 and between DA and PVG that could contribute to the phenotypic difference. However, even between the very similar $\mathrm{DA} / \mathrm{O}$ and $\mathrm{DA} / \mathrm{K}$ there is a difference in sensitivity to arthritis induction [13]. Looking closer at the polymorphic regions between $\mathrm{DA} / \mathrm{O}$ and $\mathrm{DA} / \mathrm{K}$ we could show that the strains differ primarily in regions on chromosomes 1, 2, 3, 7 and 13, which is in complete agreement with the results by Rintisch et al. However, we were able to better define the intervals, and two of the regions could be divided in two distinct regions each and we also found a new region on chromosome 5 that differs between these sub-strains (Figure 5 and Table 3). In total, these eight regions include approximately $38 \mathrm{Mbp}$ and contain 302 genes of which 78 have nsSNVs or stop codon variants. Congenic data showed no effect on disease sensitivity from the region on chromosome 3 [13], hence the variants(s) causing the different arthritis susceptibility are more likely to be located on the other chromosomes, harboring in total 122 genes (Table 3 ).

To infer if the regions of differences are contaminations from earlier crosses or hyper polymorphic regions, we compared the SNVs in the regions with the STAR genotypes of a number of other strains [37]. SNV comparisons show that $\mathrm{DA} / \mathrm{K}$ or $\mathrm{DA} / \mathrm{O}$ displays an alternating pattern of identical sequence to ACI in each of the identified intervals (Table 3). The patchy pattern of the diverging regions between the two DA strains is most likely the effect of the strains being separated and inbred separately before the DA strain was completely homozygous for all chromosomes.

The origin of the DA strain is often reported to be unknown but it has been documented to be derived from a stock from a Dr. T.T. Odell, Jr. at Oak Ridge 

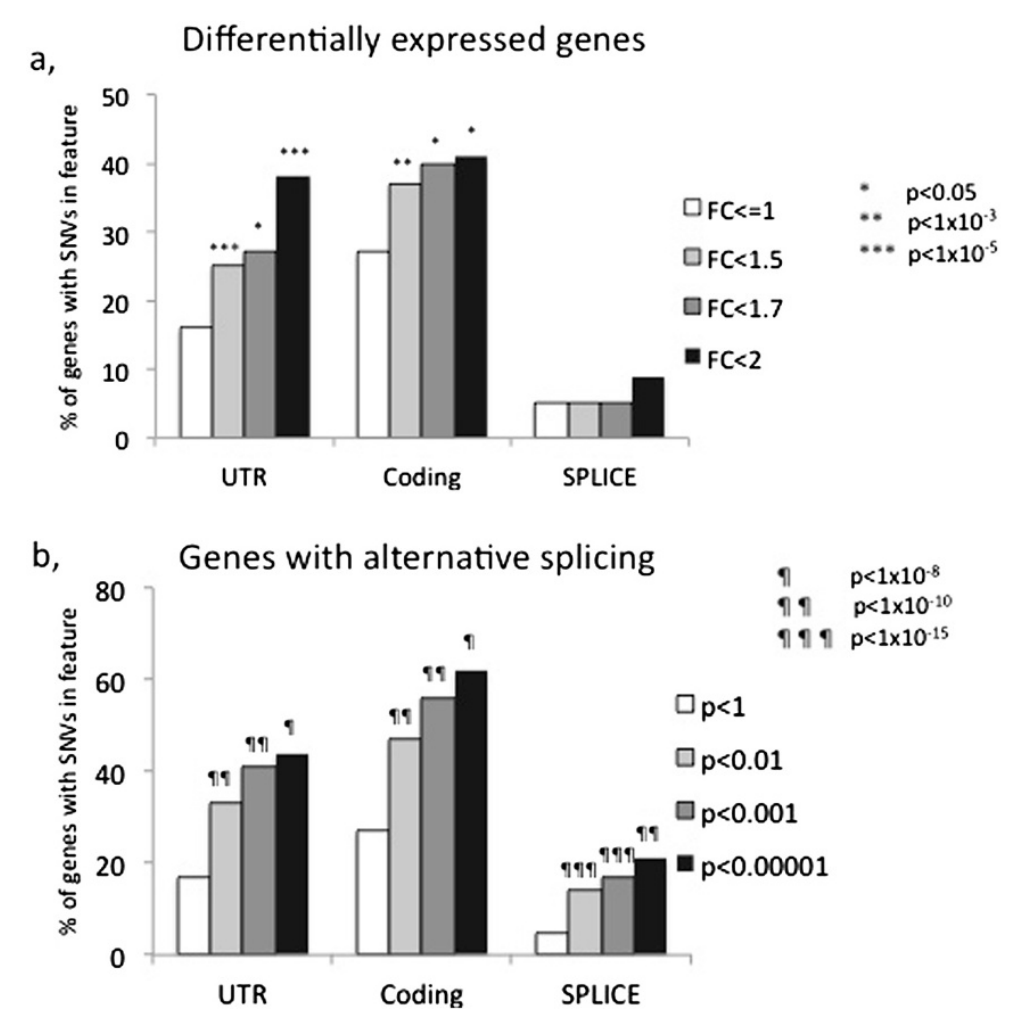

Figure 4 The association of SNVs in different gene regions and differential expression or splicing. Association of SNVs in different gene regions and differential expression or splicing, as reported in Gillett et al. [38]. The fractions of genes that have SNVs in i) coding region, ii) UTR or iii) splice sites were measured. $\mathbf{a}$, Genes predicted to be differentially expressed between DA/K and PVG compared to genes with no differential expression in this condition. Three different levels of fold change were used to categorize differentially expressed genes, resulting in 88 genes with fold change (FC) $>2,214$ genes with FC > 1.7, 520 genes with FC > 1.5 and 14140 genes with no differential expression. b. Alternatively spliced genes compared with genes with no evidence of alternative splicing in this condition. Three significance levels were used to categorize significant alternative splicing in genes, resulting in 123 genes in the highest significance category $p<0.00001,278(p<0.01), 613(p<0.1)$ and 13208 genes that were not considered alternatively spliced.

National Laboratory, Tennessee. In 1957 Dr. Odell describes an agglutination test with an experimental set up using animals from a cross between two inbred lines that fits very well with what we now know about the DA strain [41]. The first strain for the initial intercross is an Irish coated strain that had been backcrossed for 47 generations that express the $\mathrm{D}$ antigen on their erythrocytes. This strain was most likely ACI (see Table 3). The second inbred strain in the intercross expressed the $C$ antigen instead and had only been backcrossed for nine generations. Some suggestions of the $C$ antigen strain are early generations of the E3, BUF or LEW strains, which carry this allele. The F1 progeny was then backcrossed to either the D or the $C$ strain. The D/D backcross population is most likely the founder of the D-antigen expressing Agouti coat color (i.e. DA) strain. Inbreeding was at inter-cross generation 19 in about 1965. However a subset of the DA colony was sent from Wistar to Oxford already in 1963, where it was further inbred. Thus, the two DA sub-strains were separated at generation $<19$ before the chromosomes had become homozygous which explains the dissimilar regions. It is also possible that more DA sub-strains exist in laboratories throughout the world.

\section{Functional comparison - genomic variance within inflammation associated QTLs}

Dissecting the genomic influence on inflammation requests a lot of phenotypic data. Both linkage studies and congenic mapping have identified $\sim 20$ genomic regions in the DA rat associated to inflammatory disease (Figure 2). The variation analyses of smaller QTLs, approximately 1 $\mathrm{Mb}$ in size, are described in more detail below and a schematic overview of all inflammation QTLs identified in comparisons of the three genomes irrespective of interval size are described in Table 4.

\section{Chromosome 1}

Chromosome 1 harbors two regions of QTLs for both EAE and PIA, [16,18,29,31,33,42], The fine-mapping of the two QTLs down to a shorter genomic interval has been done in EAE.

One QTL region Eea29/Pia8 is positioned close to the centromere and this region regulates both EAE and PIA. 


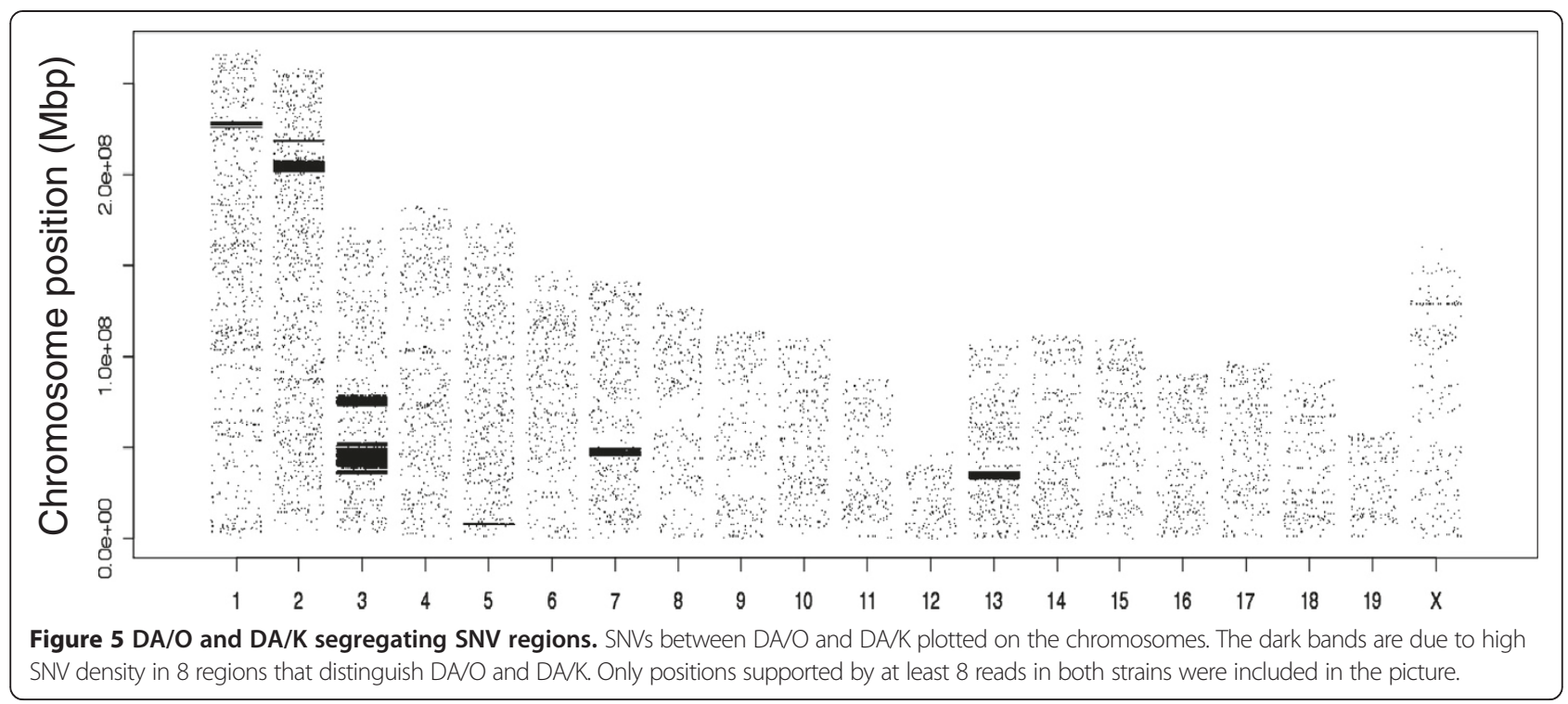

Beyeen et al. fine-mapped this QTL in EAE to less that 3 $\mathrm{Mb}$ using an AIL and they also validated the regulatory effect using a $25 \mathrm{Mb}$ congenic strain [31]. The refined Eae29/Pia8 contains 18 genes. Beyeen et al. could show differential gene expression in the genes IL22RA2 and IFNGR1 and association to IL22RA2 could be shown in a cohort of MS patients. Therefore these two genes are strong candidates as regulators of inflammatory disease and thus it is important to study all variants in the region for regulatory effects and if they coincide with conserved regions. Comparing SNVs between the strains DA and PVG in the shorter Eae29 region displayed very little variation between DA and PVG. Surprisingly, only 16 SNVs were identified between 14.5-15.1 Mb. IL22ra2 had one SNV in the second intron and Ifngrl had one SNV in the first intron. To analyze if the SNV is in a conserved segment and thus may be coinciding with a regulatory element, the conservations score for the SNVs was assessed. The SNV is considered to be conserved if the score is higher than 0.1, (http://hgdownload.soe.ucsc.edu/ goldenPath/rn4/phastCons9way/). Three of the SNVs in Eae29 coincide with highly conserved regions (Figure 6a). Further comparison of these SNVs to data from eight inbred rat strains [56] identified two SNVs in conserved regions to be unique for the DA stain and the SNV in Il22ra2 is unique for DA and one of its ancestral genomes $\mathrm{ACI}$ (Additional file 4).

The second QTL on chromosome 1 has been fine mapped in both EAE and PIA from an interval between 176-218 $\mathrm{Mb}$ and was resolved into two distinct QTLs Eae30 and Eae31. Eae31 is positioned to a region of less than $1 \mathrm{Mb}$ around $185 \mathrm{Mb}$ and Eae30 to $1 \mathrm{Mb}$ close to $128 \mathrm{Mb}$ [33]. Eae31 was fine-mapped in both EAE and PIA to five candidate genes and the region showed evidence of association to human inflammatory disease to a SNV in the IL21R. No coding polymorphisms could be

Table $3 \mathrm{DA} / O$ and DA/K differentiating regions

\begin{tabular}{|c|c|c|c|c|c|c|c|c|}
\hline Chr. & Start & End & $\begin{array}{c}\mathrm{DA} / \mathrm{O} \\
\text { similar to: }\end{array}$ & $\begin{array}{c}\mathrm{DA} / \mathrm{K} \\
\text { similar to: }\end{array}$ & $\begin{array}{l}\text { SNVs in } \\
\text { region }\end{array}$ & Genes in region & $\begin{array}{c}\text { Genes with } \\
\text { NS SNVs }\end{array}$ & Polymorphic genes \\
\hline 1 & 225.91 & 229.22 & $\mathrm{ACl}$ & F344, BUF & 3871 & 21 & 2 & Kank1, ENSRNOG00000023843. \\
\hline \multirow[t]{2}{*}{2} & 201.5 & 207.21 & LE & $\mathrm{ACl}$ & 9084 & 74 & 14 & Dennd2d, Prok1, Slc16a4, Gstm7, Clcc1, Prmt6. \\
\hline & 218.22 & 219.01 & $\mathrm{ACl}, \mathrm{E} 3$ & F344, BN & 1482 & 6 & 3 & Arhgap29, Abca4, Dnttip2. \\
\hline \multirow[t]{4}{*}{3} & 34.7 & 52.32 & $\mathrm{ACl}$ & * (F344) & 24496 & 80 & 20 & Slc39a11, Galnt5, Upp2, L:y75, Dpp4, Grb14 (Stop). \\
\hline & 73.21 & 78.08 & $\mathrm{ACl}, \mathrm{F} 344, \mathrm{BUF}$ & $*(\mathrm{WKY})$ & 6287 & 100 & 33 & C1qtnf4, Mybpc3, Ol726 (Stop), Acp2, Pacsin, Dgkz. \\
\hline & & & & & Olfactory: & 56 & 26 & \\
\hline & & & & & Other: & 44 & 7 & \\
\hline 5 & 7.1 & 8.06 & * & * & 1123 & 1 & 1 & Depdc2 (Prex2) \\
\hline 7 & 45.76 & 48.5 & SHR, F344, WKY & $\mathrm{ACl}$ & 4352 & 13 & 3 & Ptprq, ENSRNOG00000030316 (Otogl). \\
\hline 13 & 33.3 & 35.6 & $\mathrm{ACl}, \mathrm{SHR}$ & PVG, E3, BUF & 5250 & 7 & 2 & ENSRNOG00000030901, Dpp10. \\
\hline
\end{tabular}

(* unclear). 
Table 4 A summary of all coding SNVs in EAE and arthritis regulating QTLs

\begin{tabular}{|c|c|c|c|c|c|c|c|c|c|c|c|c|c|c|}
\hline Chr. & Phenotype/QTL & Start & End & $\begin{array}{l}\text { QTL length } \\
\text { (Mb) }\end{array}$ & $\begin{array}{l}\text { Ensmbl genes } \\
\text { in QTL }\end{array}$ & $\begin{array}{l}\text { All genes } \\
\text { with cSNVs }\end{array}$ & $\begin{array}{l}\text { NS } \\
\text { SNVs }\end{array}$ & $\begin{array}{l}\text { STOP c. } \\
\text { SNVs }\end{array}$ & $\begin{array}{l}\text { Splice } \\
\text { site SNVs }\end{array}$ & Indels & New candidate genes & Evidence & Strains & Reference \\
\hline 1 & PIAB & 11 & 19 & 8 & 43 & 3 & 2 & 0 & 0 & 1 & $\begin{array}{l}\text { NS SNVs in Ect2I, and } \\
\text { ATG4B, indel in ALDH8A1 }\end{array}$ & F2 & DA.PVG, & [42] \\
\hline 1 & Eae29 & 15 & 17 & 3 & 18 & 2 & 1 & 0 & 0 & 1 & $\begin{array}{l}\text { conserved SNVs in IL22RA2, } \\
\text { short indel in ALDH8A1, } \\
\text { NS SNV in ATG4B }\end{array}$ & G10, congene & DA/PVG & {$[29,31]$} \\
\hline 1 & Еае30 & 129 & 130 & 1 & 7 & 1 & 1 & 0 & 0 & 0 & RGMA, NS SNV in Top1 & G10, congene & DA/PVG & {$[29,33]$} \\
\hline 1 & CIAAG/EAEG/7 & 156 & 247 & 91 & 1343 & 225 & 136 & 2 & 93 & 12 & $\begin{array}{l}\text { stopcodon in Ltbp3 } \\
\text { and in Ms4a5 }\end{array}$ & $\mathrm{F} 2 \mathrm{BC}$ & DA/E3 & [16] \\
\hline 1 & Eae6 & 176 & 218 & 42 & 764 & 147 & 84 & 1 & 62 & 6 & stopcodon in Ms4a5 & F2 & DA/E3 & [18] \\
\hline 1 & Eae31 & 185 & 185 & 1 & 6 & 3 & 2 & 0 & 1 & 0 & $\begin{array}{l}\text { IL21R } 1 \text { cons SNV, splice } \\
\text { site in IL4R, NS SNVS } \\
\text { in Gtf3C and LOC361646 }\end{array}$ & G10, congene & DA/PVG & {$[15,29,33]$} \\
\hline 1 & Eae7 & 240 & 247 & 7 & 64 & 25 & 16 & 0 & 12 & 1 & $\begin{array}{l}\text { indel in Myof, splice site } \\
\text { SNV in Znf518a }\end{array}$ & F2 & DA/E3 & [18] \\
\hline 4 & PIA2/AIA2 & 32 & 42 & 10 & 28 & 7 & 6 & 0 & 3 & 2 & $\begin{array}{l}\text { indel in Dpp6, and frameshift } \\
\text { SNV in Tmem106b }\end{array}$ & $\mathrm{F} 2 \mathrm{BC}$ & DA/BN, E3 & {$[8,16]$} \\
\hline 4 & Eae24 & 60 & 75 & 15 & 146 & 28 & 21 & 1 & 9 & 0 & $\begin{array}{l}\text { stop in an orf in a intron of } \\
\text { Dgki }\end{array}$ & G10, congene & DA/PVG & {$[21,43,44]$} \\
\hline 4 & Eae25 & 75 & 83 & 8 & 88 & 22 & 19 & 0 & 6 & 1 & indel in Znf282 (HUB1) & G10, congene & DA/PVG & {$[21,43,44]$} \\
\hline 4 & $P \mid A 5 / C I A 3$ & 78 & 104 & 26 & 248 & 56 & 45 & 2 & 9 & 2 & 2 Stop in Igk genes & F2 BC congene & $\mathrm{DA} / \mathrm{BN}, \mathrm{E3}$ & {$[15,16]$} \\
\hline 4 & Eae26 & 83 & 104 & 21 & 206 & 28 & 24 & 0 & 5 & 2 & indel in Herc6, and RPS7 & G10, congene & DA/PVG & {$[21,43,44]$} \\
\hline 4 & Eae27 & 104 & 114 & 10 & 61 & 7 & 6 & 0 & 1 & 0 & $\begin{array}{l}\text { NS SNVs in both CD8a } \\
\text { and Cd8b }\end{array}$ & G10,congene & DA/PVG & {$[21,43,44]$} \\
\hline 4 & Eae20 & 156 & 161 & 5 & 88 & 24 & 18 & 2 & 8 & 1 & $\begin{array}{l}\text { indel in Rad52, stop in } \\
\text { Clec4b2, stop in Q6QI20 }\end{array}$ & G10, congene & DA/PVG & {$[24,44]$} \\
\hline 4 & PIA7/OIA2/CIA13 & 159 & 160 & 1 & 23 & 8 & 6 & 2 & 2 & 0 & stop in Clec4b2 & F2 congene & DA/E3,PVG & {$[45,46]$} \\
\hline 4 & Eae21 & 161 & 162 & 1 & 23 & 4 & 2 & 0 & 3 & 0 & $\begin{array}{l}\text { splice SNV in Pianp, } \\
\text { Zfp384, NS SNV Vwf }\end{array}$ & G10,congene & DA/PVG & {$[24,44]$} \\
\hline 4 & Eae22 & 162 & 172 & 10 & 137 & 34 & 27 & 1 & 14 & 1 & $\begin{array}{l}\text { Essential splice site SNV } \\
\text { in Klrc2, stop Clec2 }\end{array}$ & $\mathrm{G} 10, \mathrm{BC}$ & DA/PVG & {$[24,44]$} \\
\hline 5 & CIAA5 & 138 & 172 & 34 & 554 & 113 & 92 & 1 & 27 & 4 & $\begin{array}{l}\text { Stop in orf, indel in Nmnat1, } \\
\text { Myom3, SZT2 }\end{array}$ & $\mathrm{F} 2 \mathrm{BC}$ & DA/E3 & {$[15,16,18]$} \\
\hline 6 & PIA3/eaeg & 117 & 144 & 31 & 249 & 70 & 55 & 1 & 16 & 6 & stop in F1M0Z7_RAT & F2 congene & DA/E3 & {$[15,16,18]$} \\
\hline 7 & PIA13 & 62 & 78 & 16 & 116 & 15 & 12 & 0 & 2 & 1 & indel in Ptdss1 & F2 & DA/E3 & {$[15,16,18]$} \\
\hline 8 & PIA14 & 79 & 87 & 8 & 53 & 11 & 8 & 0 & 3 & 0 & splice site in Lrrc1, Ick, Eef1a1 & F2 & DA/E3 & {$[15,16,18]$} \\
\hline 10 & Vra4/Eae & 0 & 11 & 11 & 94 & 13 & 11 & 0 & 2 & 0 & no coding SNVs in Ciita & congene & DA/PVG & {$[47,48]$} \\
\hline 10 & Eae18a & 55 & 67 & 12 & 303 & 67 & 47 & 1 & 20 & 2 & $\begin{array}{l}\text { stop in krt18-b, } 2 \text { NSC and } \\
\text { splice site SNV in Nos2 }\end{array}$ & $\begin{array}{l}\mathrm{G} 7, \mathrm{G} 10, \\
\text { congene }\end{array}$ & DA/PVG & {$[20,22,25]$} \\
\hline
\end{tabular}


Table 4 A summary of all coding SNVs in EAE and arthritis regulating QTLs (Continued)

\begin{tabular}{|c|c|c|c|c|c|c|c|c|c|c|c|c|c|c|}
\hline 10 & Eae18b & 67 & 72 & 5 & 68 & 22 & 12 & 0 & 10 & 2 & CCL11 conserved SNVs & G7,G10,cong. & DA/PVG & {$[20,25,30,49]$} \\
\hline 10 & $\begin{array}{l}\text { CIA5A OIA3 } \\
\text { PIA1O EAN5 }\end{array}$ & 95 & 110 & 15 & 214 & 36 & 29 & 0 & 8 & 3 & $\begin{array}{l}\text { Cd300 hyper polymorphic } \\
\text { regions, indel in Fdxr, } \\
\text { Acox1, Tnrc6c }\end{array}$ & $\begin{array}{l}\text { G10 F2 } \\
\text { congene }\end{array}$ & DA/PVG & {$[14,50]$} \\
\hline 11 & Pia27, RF & 84 & 86 & 2 & 53 & 6 & 4 & 0 & 2 & 1 & Essential splice site in Lac2 & F2 congene & DA/E3 & [51] \\
\hline 12 & Eae5 & 20 & 24 & 4 & 70 & 16 & 11 & 0 & 5 & 0 & $\begin{array}{l}\text { NCF1, CLN4, splice } \\
\text { site SNV i Gtfi1 }\end{array}$ & G7, congene & DA/PVG & {$[28,49]$} \\
\hline 12 & PIA4/NCF1 & & & * & & & 1 & & & & NCF1 NS SNV aa153 & congene & DA/E3 & {$[16,52]$} \\
\hline 14 & $\begin{array}{l}\text { PIA6/EAE10/ } \\
\text { CIAA7 }\end{array}$ & 32 & 103 & 71 & 408 & 39 & 25 & 0 & 12 & 3 & $\begin{array}{l}\text { NS SNV TIr10, Igfbp3, indel } \\
\text { Aebp1, Apex2 }\end{array}$ & $\mathrm{F} 2$ & DA/E3 & {$[53,54]$} \\
\hline 15 & Eae19 & 83 & 97 & 14 & 33 & 7 & 7 & 0 & 1 & 0 & $\begin{array}{l}\text { Lmo7, Tbc1d4, Mycbp2, } \\
\text { Uchl3, Slitrk6 }\end{array}$ & G7,congene & DA/PVG & {$[20,26]$} \\
\hline 17 & Eae23a & 36 & 57 & 21 & 180 & 13 & 12 & 0 & 1 & 0 & $\begin{array}{l}\text { NS SNVs in Ripk1, Serpinb1a, } \\
\text { Gpx6, splice-SNV in Agtr1a }\end{array}$ & G10, cong. & DA/PVG & {$[29,32,55]$} \\
\hline 17 & Eae23b & 57 & 66 & 9 & 49 & 11 & 8 & 1 & 3 & 1 & stop in Prelid1 & G10, cong. & DA/PVG & {$[29,32,55]$} \\
\hline 20 & Pial & 3 & 5 & 2 & 114 & 50 & 40 & 1 & 16 & 0 & $\begin{array}{l}\text { NS SNVs in Ncr3, Lst1, RT1-Ba, } \\
\text { Tap2, Psmb8, Tap1, Psmb9, } \\
\text { Stop in RT1-CE4 }\end{array}$ & $\mathrm{F} 2$ & $\begin{array}{l}\text { DA/E3, PVG } \\
\text { DA/LEW,BN }\end{array}$ & {$[8,15]$} \\
\hline 20 & Eael & 5 & 7 & 2 & 55 & 14 & 8 & 0 & 4 & 3 & $\begin{array}{l}\text { NS SNVs in Tapbp, RT1-A2, } \\
\text { RT1-A2 frameshift } \\
\text { mutation in Grm3 }\end{array}$ & $\mathrm{F} 2$ & $\begin{array}{l}\text { DA/E3, PVG } \\
\text { DA/LEW,BN }\end{array}$ & {$[18]$} \\
\hline
\end{tabular}




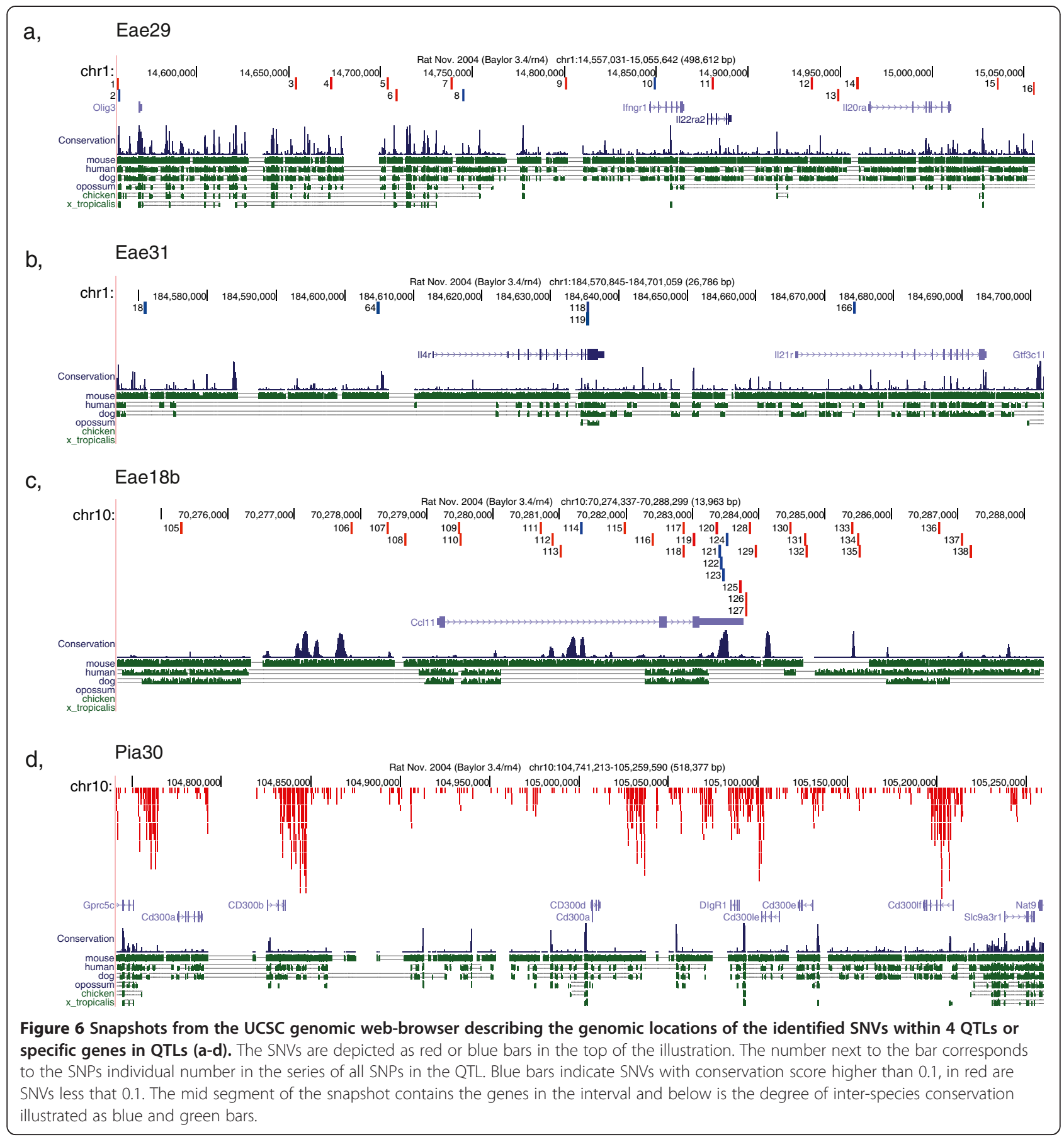

identified in the IL21R gene in the rat, but the ILARA gene had a splice site SNV. Four SNVs are unique to DA (Additional file 4). In addition, two other genes in the region, Gtf3c and LOC361646, displayed numerous nsSNVs. Further, looking at SNVs in conserved regions identified 5 potentially regulating SNVs (Figure $6 \mathrm{~b}$ ). The $I L 4 R A$ gene also contains two SSNVs, whereas the IL21R gene contains one potentially regulating $\mathrm{SNV}$ in an intron (conservation score 0.45).
In the Nohra et al. study [33], an additional 1.1 Mb EAE specific QTL Eae30 close to the RGMA gene was identified in a G10 AIL. Interestingly, there was suggestive association to the human RGMA gene also in an MS cohort. There are 48 polymorphisms between DA and PVG in RGMA. Ten of the variants are of potential interests; three SNVs in conserved regions and one synonymous SNV in the last exon. Four SNVs in the region are unique for DA/ ACI (Additional file 4). 


\section{Chromosome 4}

Rat chromosome 4 is one of the most QTL dense regions in the DA genome. Three regions have been linked to EAE and arthritis. The QTL Pia5/Eae24-27 have also been linked to experimental diabetes [57] and uveitis [58]. There is also evidence that the chromosome has regions of epistatic genetic interactions [43].

The original Pia5/Eae24-27 locus is more than $20 \mathrm{Mb}$ and covers 250 to 500 genes depending on the study and disease model $[16,43]$. Among the genes in this region are TCRBV, Ig Kappa genes and IL23R, with potential profound importance in immune regulation. In 2010 Marta et al. used a combination of congenic lines as well as an advanced intercross line to dissect disease regulation in this region. They showed that the effect on disease regulation was larger than the effect from any of the smaller congenic strains, however one small $(1.25$ $\mathrm{Mb}$ ) congenic strain (R23) mediates a major part of the regulatory effect from this region. No coding variations could be identified between DA and PVG in this region, which indicates that the disease regulating variation is regulatory. Indeed, this region is very conserved between species and of the 1810 SNVs in the interval 188 coincided with conserved genomic intervals. Not surprisingly, many of the genes in the region have important function in embryonic development.

Next, the arthritis QTL Oia2/Pia7 at 159.46-160.0 $\mathrm{Mb}$ is known to be a strong regulator of adjuvantinduced arthritis such as OIA or PIA $[42,45,46]$. Further, this arthritis QTL coincides with the EAE QTLs EAae20-21 [24]. The region harbors the APLEC complex, which encodes a set of C-type lectin receptor genes expressed on antigen presenting cells. Most of the APLEC genes have been shown to be differentially expressed after stimulation with a number of immune-triggering stimulants [45,59]. There are a number of coding polymorphisms in the APLEC complex encoded genes. One generates a premature stopcodon in Clec4b2 in the DA genome and is certainly a plausible candidate to mediate the disease phenotype. However, four other APLEC encoded genes have nonsynonymous SNVs between DA and E3/PVG. Furthermore, a total of 832 SNVs could be identified in the $550 \mathrm{~kb}$ consensus region and 33 polymorphisms lie within conserved regions in or close to genes. Neither of the SNVs in the APLEC complex are unique to DA but are shared between at least five other inbred genomes (Additional file 4) [56]. One region at 159.955 $\mathrm{kb}$ has the maximum conservation score $=1$, according to the phastCons9way, and could be a regional enhancer for the APLEC genes in the region. This region harbors two SNVs. This region needs to be analyzed further to conclusively determine weather this is an enhancer or not.

\section{Chromosome 10}

Chromosome 10 harbors at least four susceptibility genes for experimental inflammatory disease. Proximal to the centromere is the Vra1/Ciita gene locus [47,48], which is part of a haplotype identified to regulate levels of MHC class II expression, and which was also reported to be associated with chronic inflammatory disease [48]. The variant underlying the effect has however not been identified. Ciita contains no nsSNVs between DA and PVG. However, there are three synonymous coding SNVs that may influence the expression levels of which two are unique for E3/PVG (Additional file 4). In addition, there are a number of polymorphisms in conserved regions with potentially regulatory effect on the gene. The $19 \mathrm{~kb}$ upstream promoter of Ciita harbors two very conserved regions with $10 \mathrm{SNVs}$ of which one is unique to E3/PVG.

The mid-part of chromosome 10 has been associated with both EAE and arthritis Eae18/Cia5/Oia3 [25,50,60]. Eae18 QTL was fine-mapped using two AILs, G7 and G10, which divided the QTL in two QTLs, Eae18a and Eae18b [25]. EAE18a was fine-mapped to $1.1 \mathrm{Mb}$ harboring 13 genes at 58.2-59.3 Mb [22]. Two nsSNVs in Fam64a and ENSRNOG00000037371, as well as two SNVs in splicesites of RGD1304728 and Smtln2 were identified in the Eae18a locus, in addition to several potentially regulating SNVs.

Eae $18 b$ was fine-mapped to a $0.88 \mathrm{Mb}$ region between 70.2-71.0 Mb in a G10 AIL [49]. Two genes in this region $C c l 2$ and $C c l 11$ showed differential expression. Interestingly, differential expression of $\mathrm{Ccl} 2$ has also been observed between MS patients and controls. However in a functional characterization study of the Eae18b congenic strain, Ccl11 was conclusively identified to be regulating many different disease pathways in this strain [30]. Ccl11 has six SNVs in the 3'UTR of which four are in conserved sequences; the gene also has one conserved intronic SNV and one synonymous SNV (Figure 6c).

In experimental arthritis a QTL has been identified in both DA/PVG and DA/F344 crosses on chromosome 10 $[14,50,60]$. This arthritis specific QTL was fine-mapped in pristine-induced arthritis using an AIL G10 [14]. Also for this QTL the locus was separated in to two regions. Interestingly the second $1.5 \mathrm{Mb}$ region coincided with a region with $\mathrm{Cd} 300$ like genes, which contain distinct regions of very high variation between DA and the other strains (Figure $6 \mathrm{~d}$ ). The aggregation of SNVs in the vicinity of $C d 300$ genes may be an indication of structural variations in the region and needs to be further studied, however these genes could have a significant influence on the regulation mediated by this region. Interestingly this locus was not mapped in any of the DAxE3 F2 crosses, which suggests that the regulating polymorphism(s) could be unique to the PVG strain. In the other region Pia30, 114 SNVs were identified that 
segregated E3/DA and PVG alleles, of which most are intronic or intergenic SNVs in or near the Rpl38 and Ttyh2 genes.

\section{Chromosome 12}

The first arthritis regulating QTL to be cloned and positioned to one polymorphism is the Pia4, which was identified to be regulating chronic inflammation by a nonsynonymous SNV in the Ncf1 gene, altering the amino acid at position 153 [52]. It was originally mapped using both PIA (Pia4) [8] and EAE models (Eae5/Eae11) [18,23]. The gene was identified using a congenic strain with E3 alleles between 23.476-23.730 Mb and harbors three genes. Here, a total of 377 SNVs were detected between DA and PVG/ E3 in the Pia4 region. Five of them are coding variants, of which one is non-synonymous and one is annotated to be in a splice site of Gtf2i. Moreover, $7 \mathrm{SNVs}$ are located in UTRs of which 5 are in the 3'UTR of the Ncf1 gene, but they have low conservation scores. Five SNVs are in potentially conserved regions, but only one of them, the nsSNV, is in Ncf1. Hence, the genome sequences support the previous findings that the inflammation regulatory effect from this congenic is mediated by the Ncf1 nsSNV [61].

\section{Conclusions}

DA rats are particularly susceptible to the induction of a number of chronic inflammatory diseases. There is a modest difference in arthritis susceptibility between the two strains where $\mathrm{DA} / \mathrm{O}$ is slightly more susceptible. Here we identified eight polymorphic regions between two substrains of DA; DA/K and DA/O together covering $38 \mathrm{Mb}$ of genomic sequence. Of the variable regions, $23 \mathrm{Mb}$ are located on chromosome 3 and by using a $\mathrm{DA} / \mathrm{O} . \mathrm{chr} \mathrm{DA} / \mathrm{K}$ congenic strain these regions were excluded as important in arthritis regulation [13], and thus the regulatory effect should come from the remaining $15 \mathrm{Mb}$ variable regions between $\mathrm{DA} / \mathrm{O}$ and $\mathrm{DA} / \mathrm{K}$.

According to the rat genome database more that 50 inflammatory disease related QTLs have been identified in the DA rat. Here we have used the next-generation sequencing of the DA genome and inflammatory disease resistant E3 and PVG to investigate 10 fine-mapped QTLs and closely catalogue the complete set of variations in these regions. This study has identified a number of interesting non-synonymous or regulatory variants within these QTLs.

For the already positionally cloned gene, $N c f 1$, in the Pia4 QTL on chromosome 12, no additional regulatory SNVs were identified in the proximal region of Ncf1 that are likely to contribute to the regulation of inflammation in the region. Hence, this further enhances the importance of the previously detected nsSNV (coding for aa153 of the protein) in the regulation of experimental inflammatory disease.
Two of the inflammatory-disease regulating regions analyzed here; the Vra1/Ciita and Eae25/R23 loci are completely devoid of coding SNVs, but do contain several SNVs in conserved regions, indicating regions of regulatory function.

Four of the QTLs (Eae29, Eae30, Eae31 and Eae18b) have strong candidate genes that have been identified to be differentially expressed between DA and PVG as well as associated to chronic inflammatory disease in human cohorts. These gene-regions were analyzed for regulatory polymorphisms. Eae29 has three very good regulatory SNV candidates that should be assessed for disease regulation in the vicinity of IL22ra2. The expression of IL22ra2 has been demonstrated to differ between the strains implicating difference in regulatory regions [31]. IL22RA2 is now one of the well-established MS risk genes [62]. Eae30 has one non-synonymous SNV in a topoisomerase like gene, however this gene may not be the disease-regulating gene in the interval. $R G M A$, which is the top candidate gene in the region, contains 4 conserved regions with possible regulatory SNVs. The top candidate gene for the Eae31 locus is Il21r. This gene has only one identified SNV with potential regulatory function in the first intron of the gene. Eae31 also contains a splice site SNV in the Il4ra gene plus two potential regulating SNVs that also should be tested for EAE regulation. The QTL Eae18b harbors the Ccl11 gene that have shown strong immuneregulatory effects in inflammatory disease [30]. Ccl11 contains five highly conserved SNVs and particularly four SNVs in the 3'UTR are strong candidates to be regulators of differential expression.

The APLEC locus on chromosome 4 harbors five nsSNVs in four genes. This region contains very few conserved regions, however a new impending regulatory region $50 \mathrm{~kb}$ upstream of the last gene (Mincle) in the complex was identified that contains two SNVs in the middle of the conserved region. This region has to be analyzed further to fully comprehend if and how it could regulate all genes in the region.

A hyper-variable region in Pia30 on chromosome 10 was also identified. This region contains four SNV dense regions of about $10 \mathrm{~kb}$ in size each. These variable regions occur in the extended 3'UTR of Cd300 genes, $C d 300 b$ and $C d 300 f$ in particular. This enrichment of SNVs in a short interval may perhaps be explained by sequence duplications/divergence.

By combining information for the most interesting SNVs in the herein analyzed QTLs with SNV information from an eight genome sequencing study of inbred rats [56], we identified a number of SNVs unique for inflammation susceptible DA and the inflammatory disease resistant PVG and E3 strain. Three QTLs had DA or DA/ACI unique SNVs and one had E3/PVG unique SNVs. Out of the eight QTLs that were used in this comparison only four had 
unique SNVs. This is somewhat expected since one of the few cloned chronic inflammatory disease regulating SNV, in the Ncf1 gene, also is present in the inbred strains BUF, F344 and WKY. The strain BUF is susceptible to both arthritis and EAE whereas both F344 and WKY are resistant to experimental arthritis. The disease regulation mediated by this SNV is however very strong and has been confirmed to be disease regulating also in mice. This demonstrates that additional protective genes in the genome may mask even very strong disease enhancing SNV effects.

In a genotype to phenotype perspective, the combined effect from the QTLs has profound functional implications. In short, both the adaptive and innate immunity is affected; The Ncf1 gene is involved in the first defense against infections and triggering the immune system. Both the CD300 and the APLEC encoded genes are important pattern recognition receptors involved in antigen uptake and Ciita is important in regulating antigen presentation. The chemokine Ccl11 and the cytokine receptors Il21r and Il22ra2 are important in modulating the immune responses leading to inflammation. Il21r and Il22ra2 are particularly important regulators of activated $\mathrm{T}$ cells. In conclusion the 10 QTLs represent regions of important disease regulation and the combined effect explains a substantial part of the pro-inflammatory phenotype that is characteristic of the DA strain.

The full genomic sequence of DA/O, DA/K, E3 and PVG constitutes an invaluable resource in the understanding of how polymorphisms in the DA genome contribute to disease susceptibility and this genetic blueprint of an inflammation permissive rat strain will also be important in the understanding of the human etiologies for chronic inflammatory disease.

\section{Methods \\ Next-generation sequencing}

Liver samples from 1 female rat per strain was used for all runs. The sequences were generated in 3 separate runs. The first run (august 2009) was achieved using a SOLiD ${ }^{\mathrm{tm}} 3$ sequencer with 1 full slide per sample. The Mate-pair library protocol was used to generate $2 \times 50$ bp reads, with $2-3 \mathrm{~kb}$ insert size. A Hydro-shear was used for fragmentation. The libraries were produced after 11 cycles of amplification. The second run (September 2010) was performed using a SOLiD ${ }^{\mathrm{mw}} 4$ and generating 2 Mate-pair libraries per genome, one with $1 \mathrm{~kb}$ insert size and one with $4-4.5 \mathrm{~kb}$ insert sizes. $1 / 4$ of a slide was used for each library and the libraries were amplified 10-15 times. The DNA samples were fragmented using a Covaris S2. The last sequencing run using the Fragment library protocol was done on a SOLiD $^{\mathrm{m}} 5500$ (June 2011). 3 lanes of 75 X 35 bp reads were run per sample. Fragmentation to $150-200$ bp was achieved by a Covaris $\mathrm{S} 2$ with 6 cycles of amplification. All libraries in the study were quality controlled on an Agilent Bioanalyser High sensitivity Chip + qPCR.

\section{Mapping}

The reads were aligned to the $\mathrm{BN}$ reference assembly (Rnor3.4) with the BWA (v0.5.9) aligner (-c - $25-\mathrm{k} 2-\mathrm{n}$ 10). Mapped reads from all libraries were merged before SNV calling. The yield of sequence mapping to the genome was $48.9 \mathrm{~Gb}$ for DA/O, 50.8 Gb for DA/K, $59.9 \mathrm{~Gb}$ for E3/ han and $51.8 \mathrm{~Gb}$ for PVG/1AV1.Kini (Additional file 1).

\section{SNV/Indel calling}

SNV and short indel calling was done with a strategy developed by Guryev [36] based on Samtools pileup [63]. Duplicate reads (starting at the same position) were discarded. Next, each SNV should be supported by at least three calls with a quality $>10$. In addition, we used only SNVs where at least $75 \%$ of the reads support the nonreference allele ( $40 \%$ for indels). Finally, SNVs that differed between the reference and the resequencing of the original reference rat (Eve), were removed since these are likely to be errors in the reference. This resulted in a total of 5.2 M SNVs and 0.66 M short indels (< $10 \mathrm{bp})$, of which about $57 \%$ were deletions and $43 \%$ insertions. A "high-quality SNV set" was compiled of SNVs with at least 8 X coverage. About $97 \%$ of the genome was covered by at least 3 calls and $85 \%$ by 8 or more.

The functional annotations of all SNVs were predicted with the Ensembl Variant Effect Predictor [64].

These strains have been inbred for many generations and should be homozygous at nearly all positions. Therefore we excluded approximately $0.9 \mathrm{M}$ positions per strain where $25-75 \%$ of the reads supported the variant allele. Almost $10 \%$ of these variants are detected in regions with high coverage ( $>30 \mathrm{X}$ ), compared to $<1 \%$ for homozygous SNVs, and may be due to duplications, as suggested previously [40]. Further, we found that 7\% of the heterozygous SNVs in DA/O (coverage 9-25X) were called as homozygous $\mathrm{SNVs}$ in $\mathrm{DA} / \mathrm{K}$, whereas $1 \%$ were called as reference. Hence, some heterozygous SNV calls are likely true SNVs which are missed due to low coverage and errors in sequencing/alignment.

To estimate the SNV calling sensitivity we compared our SNVs with a set of 20284 SNVs typed by the STAR consortium [37]. In this set, 11241, 11037 and 11253 SNVs differed between BN and DA, E3 and PVG, respectively, of which, we detected between $96.8-97.8 \%$ in all strains. We also sequenced a number of SNV dense regions with conventional Sanger sequencing. Out of the 178 SNVs detected by Sanger sequencing, 171 could be detected by the SOLiD sequencing, whereas two were predicted by less than $75 \%$ of the reads and thus were false negatives. No false positives were found with SOLiD in these regions. 
The sensitivity of indel calling could not be estimated using STAR genotypes and the Sanger sequenced regions did not contain any indels, however it is likely that the sensitivity is substantially lower. Indeed, we found that only $66 \%$ of the indels called in DA/O were confirmed in $\mathrm{DA} / \mathrm{K}$.

\section{CNV calling}

Copy number variation (CNVs) due either to deletions or duplications of regions. were predicted with DWACseq version 0.56 to identify CNVs. This program counts the reads in a window of dynamic size and compares these counts for two strains. We counted only uniquely mapped reads and used a ratio below 0.3 for deletions and above 1.6 for duplications. To better distinguish CNVs from repetitive regions, we only allowed regions with one strain having a mean coverage around the mean genome coverage $\left( \pm 0.5^{*}\right.$ mean coverage). Further, regions were only predicted as deletions if the number of bases lacking coverage differed by at least $10 \%$ between the strains.

\section{Ethics statement}

All experiments in this study were approved and performed in accordance with the guidelines from the Swedish National Board for Laboratory Animals and the European Community Council Directive (86/609/EEC) under the ethical permit N332/06entitled 'Genetic regulation, pathogenesis and therapy of EAE, an animal model for multiple sclerosis', which was approved by the North Stockholm Animal Ethics Committee (Stockholm snorra djurförsöksetiska nämnd). Rats were tested according to a healthmonitoring program at the National Veterinary Institute (Statens Veterinärmedicinska Anstalt, SVA) in Uppsala, Sweden.

\section{QTL analysis}

QTLs smaller than $1 \mathrm{Mb}$ in interval were selected for finer SNV analysis. SNVs were visualized using the addcustom track function in the UCSC web browser. The conservation scores (phastCons9way) where downloaded from the UCSC. http://hgdownload.soe.ucsc.edu/goldenPath/ $\mathrm{rn} 4 /$ phastCons9way/. In order to retrieve information on unique SNVs in the smallest QTLs, conserved SNVs or nsSNVs in the QTLs were compared to eight inbred rat strains [56] in a 13 genome comparison.

\section{Accession numbers}

The sequence data for all four genomes will be available from the European Bioinformatics Institute short read archive under the accession number: ERP0004908. All variants identified in this study will be available from the rat genome database (http://rgd.mcw.edu).

\section{Additional files}

Additional file 1: Yield and coverage for sequence libraries. Table describing the different libraries that were created, and the yield and genome coverage from sequencing.

Additional file 2: Stop-gained or stop-lost nsSNVs. Table with nsSNVs that generates stop-gained or stop-lost.

Additional file 3: Insertions and deletions. Table describing insertions and deletions identified in the sequencing study.

Additional file 4: A 16 rat strain SNV analysis within eight inflammation associated QTLs. Table including SNV information for 9 rat strains [56] within eight of the smallest QTLs discussed in the Results section. The SNV that are included in the table are all identified nsSNVs, sSNVs splice-site variants and conserved SNVs.

\section{Abbreviations}

Chr: Chromosome; PIA: Pristane-induced arthritis; EAE: Experimental autoimmune encephalomyelitis; OIA: Oil-induced arthritis; DAVO: DA/OlaHsd DA/K, DA/hanKini; QTL: Quantitative trait locus; SNV: Single nucleotide variation; SY-SNV: Synonymous SNV; NS-SNV: Non-synonymous SNV; CSNV: SNV in coding region.

\section{Competing interests}

No financial or non-financial competing interests exist between the authors of this manuscript.

\section{Authors' contributions}

$\mathrm{LB}, \mathrm{DE}, \mathrm{MJ}, \mathrm{TO}, \mathrm{RH}$ all made substantial contributions to conception and design of the study, Sample preparations were performed by LB and MJ, Bioinformatics and acquisition of data was performed by $D E$, analysis and interpretation of data were performed by LB, and DE. LB made the first draft of the manuscript and $L B, D E, M J, R H$ and TO have all been involved in revising the manuscript critically and contributed with important intellectual content. All authors have given final approval of the final version to be published.

\section{Acknowledgements}

We thank Inger Jonansson and Christian Tellgren-Roth at the Uppsala genome center and sciLifeLab in Uppsala for the SOLiD sequencing and mapping the reads to the Rnor3.4 reference genome. We thank Carlos Palestro for taking care of animals. This study was supported by grants from King Gustaf V:s 80 years, Swedish Rheumatism Association, Swedish Research Council, Knut and Alice Wallenbergs' Foundation, the AFA foundation, Swedish Strategic Science Foundation, the EU Masterswitch (grant number: HEALTH-F2-2008-223404) and Euratrans projects (HEALTH-F4-2010-241504).

\section{Author details}

${ }^{1}$ Medical Inflammation Research, Department of Medical Biochemistry and Biophysics, Karolinska Institutet, Stockholm, Sweden. ${ }^{2}$ Center for Molecular Medicine, Department of Clinical Neuroscience, Neuroimmunology Unit, Karolinska Institutet, Stockholm, Sweden. ${ }^{3}$ Unit of Medical inflammatory disease, Department of Medical Biochemistry, Karolinska Institutet, Scheeles väg 2, B2 plan 4, 17177 Stockholm, Sweden.

Received: 10 January 2013 Accepted: 24 March 2014 Published: 21 May 2014

\section{References}

1. Atanur SS, Birol I, Guryev V, Hirst M, Hummel O, Morrissey C, Behmoaras J, Fernandez-Suarez XM, Johnson MD, McLaren WM, Patone G, Petretto E, Plessy C, Rockland KS, Rockland C, Saar K, Zhao Y, Carninci P, Flicek P, Kurtz T, Cuppen E, Pravenec M, Hubner N, Jones SJM, Birney E, Aitman TJ: The genome sequence of the spontaneously hypertensive rat: analysis and functional significance. Genome Res 2010, 20:791-803.

2. Seldin MF, Amos Cl, Ward R, Gregersen PK: The genetics revolution and the assault on rheumatoid arthritis. Arthritis Rheum 1999, 42:1071-1079.

3. Hauser SL, Oksenberg JR: The neurobiology of multiple sclerosis: genes, inflammation, and neurodegeneration. Neuron 2006, 52:61-76.

4. Fernando MMA, Stevens CR, Walsh EC, De Jager PL, Goyette P, Plenge RM, Vyse TJ, Rioux JD: Defining the role of the MHC in autoimmunity: a review and pooled analysis. PLOS Genet 2008, 4:e1000024. 
5. Manolio TA, Collins FS, Cox NJ, Goldstein DB, Hindorff LA, Hunter DJ, McCarthy MI, Ramos EM, Cardon LR, Chakravarti A, Cho JH, Guttmacher AE, Kong A, Kruglyak L, Mardis E, Rotimi CN, Slatkin M, Valle D, Whittemore AS, Boehnke M, Clark AG, Eichler EE, Gibson G, Haines JL, Mackay TFC, McCarroll SA, Visscher PM: Finding the missing heritability of complex diseases. Nature 2009, 461:747-753.

6. Trentham DE, Townes AS, Kang AH: Autoimmunity to type II collagen an experimental model of arthritis. J Exp Med 1977, 146:857-868.

7. Holmdahl R, Goldschmidt TJ, Kleinau S, Kvick C, Jonsson R: Arthritis induced in rats with adjuvant oil is a genetically restricted, alpha beta T-cell dependent autoimmune disease. Immunology 1992, 76:197-202.

8. Vingsbo-Lundberg C, Nordquist N, Olofsson P, Sundvall M, Saxne T, Pettersson U, Holmdahl R: Genetic control of arthritis onset, severity and chronicity in a model for rheumatoid arthritis in rats. Nat Genet 1998, 20:401-404.

9. Lorentzen JC, Andersson M, Issazadeh S, Dahlman I, Luthman H, Weissert R, Olsson T: Genetic analysis of inflammation, cytokine mRNA expression and disease course of relapsing experimental autoimmune encephalomyelitis in DA rats. J Neuroimmunol 1997, 80:31-37.

10. Dahlman I, Wallström E, Jiao H, Luthman H, Olsson T, Weissert R: Polygenic control of autoimmune peripheral nerve inflammation in rat. J Neuroimmunol 2001, 119:166-174

11. Sun B, Sun SH, Chan CC, Caspi RR: Evaluation of in vivo cytokine expression in EAU-susceptible and resistant rats: a role for IL-10 in resistance? Exp Eye Res 2000, 70:493-502.

12. Rose NR: Differing responses of inbred rat strains in experimental autoimmune thyrioditis. Cell Immunol 1975, 18:360-364.

13. Rintisch C, Holmdahl R: DA rats from two colonies differ genetically and in their arthritis susceptibility. Mamm Genome 2008, 19:420-428.

14. Bäckdahl L, Guo JP, Jagodic M, Becanovic K, Ding B, Olsson T, Lorentzen JC: Definition of arthritis candidate risk genes by combining rat linkagemapping results with human case-control association data. Ann Rheum Dis 2009, 68:1925-1932.

15. Olofsson P, Holmberg J, Pettersson U, Holmdahl R: Identification and isolation of dominant susceptibility loci for pristane-induced arthritis. $\mathrm{J}$ Immunol 2003, 171:407-416.

16. Olofsson P, Lu S, Holmberg J, Song T, Wernhoff P, Pettersson U, Holmdahl R: A comparative genetic analysis between collagen-induced arthritis and pristane-induced arthritis. Arthritis Rheum 2003, 48:2332-2342.

17. Holmberg J, Tuncel J, Yamada H, Lu S, Olofsson P, Holmdahl R: Pristane, a non-antigenic adjuvant, induces MHC class II-restricted, arthritogenic T cells in the rat. J Immunol 2006, 176:1172-1179.

18. Bergsteinsdottir K, Yang HT, Pettersson U, Holmdahl R: Evidence for common autoimmune disease genes controlling onset, severity, and chronicity based on experimental models for multiple sclerosis and rheumatoid arthritis. J Immunol 2000, 164:1564-1568.

19. Yang HT, Bergsteinsdottir $K$, Wernhoff $P$, Linington C, Pettersson U, Holmdahl R: Genetic linkage analysis of the antibody responses to myelin basic protein and myelin oligodendrocyte glycoprotein in rats immunized with rat spinal cord homogenate. J Neuroimmunol 2001, 117:21-29.

20. Dahlman I, Wallström E, Weissert R, Storch M, Kornek B, Jacobsson L, Linington $C$, Luthman $H$, Lassmann $H$, Olsson T: Linkage analysis of myelin oligodendrocyte glycoprotein-induced experimental autoimmune encephalomyelitis in the rat identifies a locus controlling demyelination on chromosome 18. Hum Mol Genet 1999, 8:2183-2190.

21. Dahlman I, Lorentzen JC, de Graaf KL, Stefferl A, Linington C, Luthman H, Olsson T: Quantitative trait loci disposing for both experimental arthritis and encephalomyelitis in the DA rat; impact on severity of myelin oligodendrocyte glycoprotein-induced experimental autoimmune encephalomyelitis and antibody isotype pattern. Eur J Immunol 1998, 28:2188-2196.

22. Ockinger J, Serrano-Fernández P, Möller S, Ibrahim SM, Olsson T, Jagodic M: Definition of a 1.06-Mb region linked to neuroinflammation in humans, rats and mice. Genetics 2006, 173:1539-1545.

23. Becanovic K, Jagodic M, Sheng JR, Dahlman I, Aboul-Enein F, Wallström E, Olofsson P, Holmdahl R, Lassmann H, Olsson T: Advanced intercross line mapping of Eae5 reveals Ncf-1 and CLDN4 as candidate genes for experimental autoimmune encephalomyelitis. J Immuno/ 2006, 176:6055-6064.

24. Jagodic M, Marta M, Becanovic K, Sheng JR, Nohra R, Olsson T, Lorentzen $J C$ : Resolution of a $16.8-\mathrm{Mb}$ autoimmunity-regulating rat chromosome 4 region into multiple encephalomyelitis quantitative trait loci and evidence for epistasis. J Immunol 2005, 174:918-924.
25. Jagodic M, Becanovic K, Sheng JR, Wu X, Bäckdahl L, Lorentzen JC, Wallström E, Olsson T: An advanced intercross line resolves Eae18 into two narrow quantitative trait loci syntenic to multiple sclerosis candidate loci. J Immunol 2004, 173:1366-1373.

26. Sheng JR, Jagodic M, Dahlman I, Becanovic K, Nohra R, Marta M, lacobaeus E, Olsson T, Wallström E: Eae19, a new locus on rat chromosome 15 regulating experimental autoimmune encephalomyelitis. Genetics 2005, 170:283-289.

27. Lorentzen JC, Glaser A, Jacobsson L, Galli J, Fakhrai-rad H, Klareskog L, Luthman H: Identification of rat susceptibility loci for adjuvant-oil-induced arthritis. Proc Natl Acad Sci U S A 1998, 95:6383-6387.

28. Lorentzen JC, Klareskog L: Comparative susceptibility of DA, LEW, and LEW.1AV1 rats to arthritis induced with different arthritogens: mineral oil, mycobacteria, muramyl dipeptide, avridine and rat collagen type II. Transplant Proc 1997, 29:1692-1693.

29. Becanovic K, Wallström E, Kornek B, Glaser A, Broman KW, Dahlman I, Olofsson P, Holmdahl R, Luthman H, Lassmann H, Olsson T: New loci regulating rat myelin oligodendrocyte glycoprotein-induced experimental autoimmune encephalomyelitis. J Immunol 2003, 170:1062-1069.

30. Adzemovic MZM, Ockinger JJ, Zeitelhofer MM, Hochmeister SS, Beyeen ADA, Paulson AA, Gillett AA, Hedreul MMT, Covacu RR, Lassmann HH, Olsson TT, Jagodic MM: Expression of $\mathrm{Cl} 11$ associates with immune response modulation and protection against neuroinflammation in rats. PLOS ONE 2011, 7:e39794-e39794.

31. Beyeen ADA, Adzemovic MZM, Ockinger JJ, Stridh PP, Becanovic KK, Laaksonen HH, Lassmann HH, Harris RAR, Hillert JJ, Alfredsson LL, Celius EGE, Harbo HFH, Kockum II, Jagodic MM, Olsson TT: IL-22RA2 associates with multiple sclerosis and macrophage effector mechanisms in experimental neuroinflammation. J Immunol 2010, 185:6883-6890.

32. Stridh PP, Hedreul MMT, Beyeen ADA, Adzemovic MZM, Laaksonen HH, Gillett AA, Ockinger JJ, Marta MM, Lassmann HH, Becanovic KK, Jagodic MM, Olsson TT: Fine-mapping resolves Eae23 into two QTLs and implicates ZEB1 as a candidate gene regulating experimental neuroinflammation in rat. PLOS ONE 2009, 5:e12716-e12716.

33. Nohra R, Beyeen AD, Guo JP, Khademi M, Sundqvist E, Hedreul MT, Sellebjerg F, Smestad C, Oturai AB, Harbo HF, Wallström E, Hillert J, Alfredsson L, Kockum I, Jagodic M, Lorentzen J, Olsson T: RGMA and IL21R show association with experimental inflammation and multiple sclerosis. Genes Immun 2010, 11:279-293.

34. Raymond SL, Dodds WJ: Characterization of the fawn-hooded rat as a model for hemostatic studies. Thromb Diath Haemorrh 1975, 33:361-369.

35. Li H, Durbin R: Fast and accurate short read alignment with BurrowsWheeler transform. Bioinformatics 2009, 25:1754-1760.

36. Guryev V, Saar K, Adamovic T, Verheul M, van Heesch SAAC, Cook S, Pravenec M, Aitman T, Jacob H, Shull JD, Hubner N, Cuppen E: Distribution and functional impact of DNA copy number variation in the rat. Nat Genet 2008, 40:538-545.

37. STAR Consortium, Saar K, Beck A, Bihoreau M-T, Birney E, Brocklebank D, Chen Y, Cuppen E, Demonchy S, Dopazo J, Flicek P, Foglio M, Fujiyama A, Gut IG, Gauguier D, Guigo R, Guryev V, Heinig M, Hummel O, Jahn N, Klages S, Kren V, Kube M, Kuhl H, Kuramoto T, Kuroki Y, Lechner D, Lee Y-A, LopezBigas N, Lathrop GM, Mashimo T, et al: SNP and haplotype mapping for genetic analysis in the rat. Nat Genet 2008, 40:560-566.

38. Gillett A, Maratou K, Fewings C, Harris RA, Jagodic M, Aitman T, Olsson T: Alternative splicing and transcriptome profiling of experimental autoimmune encephalomyelitis using genome-wide exon arrays. PLOS ONE 2009, 4:e7773.

39. Huang G-J, Shifman S, Valdar W, Johannesson M, Yalcin B, Taylor MS, Taylor JM, Mott R, Flint J: High resolution mapping of expression QTLs in heterogeneous stock mice in multiple tissues. Genome Res 2009, 19:1133-1140.

40. Simonis M, Atanur SS, Linsen S, Guryev V, Ruzius FP, Game L, Lansu N, de Bruijn E, van Heesch S, Jones SJ, Pravenec M, Aitman TJ, Cuppen E: Genetic basis of transcriptome differences between the founder strains of the rat HXB/BXH recombinant inbred panel. Genome Biol 2012, 27:13(4).

41. Odell T, Tausche FG, Lindsley DL, OWEN RD: The homotransplantation of functional erythropoietic elements in the rat following total-body irradiation. Ann N Y Acad Sci 1957, 64:811-823. discussion-823-5.

42. Nordquist N, Olofsson P, Vingsbo-Lundberg C, Petterson U, Holmdahl R: Complex genetic control in a rat model for rheumatoid arthritis. J Autoimmun 2000, 15:425-432 
43. Marta M, Stridh P, Becanovic K, Gillett A, Ockinger J, Lorentzen JC, Jagodic $\mathrm{M}$, Olsson T: Multiple loci comprising immune-related genes regulate experimental neuroinflammation. Genes Immun 2010, 11:21-36.

44. Becanovic K, Bäckdahl L, Wallström E, Aboul-Enein F, Lassmann H, Olsson T, Lorentzen JC: Paradoxical effects of arthritis-regulating chromosome 4 regions on myelin oligodendrocyte glycoprotein-induced encephalomyelitis in congenic rats. Eur J Immunol 2003, 33:1907-1916.

45. Rintisch C, Kelkka T, Norin U, Lorentzen JC, Olofsson P, Holmdahl R: Finemapping of the arthritis QTL Pia7 reveals co-localization with Oia2 and the APLEC locus. Genes Immun 2010, 11:239-245.

46. Lorentzen JC, Flornes L, Eklöw C, Bäckdahl L, Ribbhammar U, Guo JP, Smolnikova M, Dissen E, Seddighzadeh M, Brookes AJ, Alfredsson L, Klareskog L, Padyukov L, Fossum S: Association of arthritis with a gene complex encoding C-type lectin-like receptors. Arthritis Rheum 2007, 56:2620-2632.

47. Harnesk K, Swanberg M, Ockinger J, Diez M, Lidman O, Wallström E, Lobell A, Olsson T, Piehl F: Vra4 congenic rats with allelic differences in the class II transactivator gene display altered susceptibility to experimental autoimmune encephalomyelitis. J Immunol 2008, 180:3289-3296.

48. Swanberg M, Lidman O, Padyukov L, Eriksson P, Akesson E, Jagodic M, Lobell A, Khademi M, Börjesson O, Lindgren CM, Lundman P, Brookes AJ, Kere J, Luthman H, Alfredsson L, Hillert J, Klareskog L, Hamsten A, Piehl F, Olsson T: MHC2TA is associated with differential MHC molecule expression and susceptibility to rheumatoid arthritis, multiple sclerosis and myocardial infarction. Nat Genet 2005, 37:486-494.

49. Ockinger JJ, Stridh PP, Beyeen ADA, Lundmark FF, Seddighzadeh MM, Oturai AA, Sørensen PSP, Lorentzen ARA, Celius EGE, Leppä W, Koivisto KK, Tienari PJP, Alfredsson LL, Padyukov LL, Hillert JJ, Kockum II, Jagodic MM, Olsson $\Pi$ : Genetic variants of CC chemokine genes in experimental autoimmune encephalomyelitis, multiple sclerosis and rheumatoid arthritis. Genes Immun 2010, 11:142-154.

50. Holm BC, Xu HW, Jacobsson L, Larsson A, Luthman H, Lorentzen JC: Rats made congenic for Oia3 on chromosome 10 become susceptible to squalene-induced arthritis. Hum Mol Genet 2001, 10:565-572.

51. Rintisch C, Ameri J, Olofsson P, Luthman H, Holmdahl R: Positional cloning of the Igl genes controlling rheumatoid factor production and allergic bronchitis in rats. Proc Natl Acad Sci U S A 2008, 105:14005-14010.

52. Olofsson P, Holmberg J, Tordsson J, Lu S, Akerström B, Holmdahl R: Positional identification of $\mathrm{Ncf1}$ as a gene that regulates arthritis severity in rats. Nat Genet 2003, 33:25-32

53. Wester L, Olofsson P, Ibrahim SM, Holmdahl R: Chronicity of pristaneinduced arthritis in rats is controlled by genes on chromosome 14 J Autoimmun 2003, 21:305-313.

54. Olofsson P, Wernhoff $P$, Holmberg J, Holmdahl R: Two-loci interaction confirms arthritis-regulating quantitative trait locus on rat chromosome 6. Genomics 2003, 82:652-659.

55. Roth MP, Viratelle C, Dolbois L, Delverdier M, Borot N, Pelletier L, Druet $\mathrm{P}$, Clanet M, Coppin H: A genome-wide search identifies two susceptibility loci for experimental autoimmune encephalomyelitis on rat chromosomes 4 and 10. J Immunol 1999, 162:1917-1922.

56. Rat Genome Sequencing and Mapping Consortium, Baud A, Hermsen R, Guryev V, Stridh P, Graham D, McBride MW, Foroud T, Calderari S, Diez M, Ockinger J, Beyeen AD, Gillett A, Abdelmagid N, Guerreiro-Cacais AO, Jagodic M, Tuncel J, Norin U, Beattie E, Huynh N, Miller WH, Koller DL, Alam I, Falak S, Osborne-Pellegrin M, Martinez-Membrives E, Canete T, Blazquez G, VicensCosta E, Mont-Cardona C, Diaz-Moran S, et al: Combined sequence-based and genetic mapping analysis of complex traits in outbred rats. Nat Genet 2013, 45(7):767-775.

57. Blankenhorn EP, Descipio C, Rodemich L, Cort L, Leif JH, Greiner DL, Mordes JP: Refinement of the Iddm4 diabetes susceptibility locus reveals TCRVbeta4 as a candidate gene. Ann N Y Acad Sci 2007, 1103:128-131.

58. Mattapallil MJ, Sahin A, Silver PB, Sun S-H, Chan C-C, Remmers EF, Hejtmancik JF, Caspi RR: Common genetic determinants of uveitis shared with other autoimmune disorders. J Immuno/ 2008, 180:6751-6759.

59. Guo JP, Bäckdahl L, Marta M, Mathsson L, Rönnelid J, Lorentzen JC: Profound and paradoxical impact on arthritis and autoimmunity of the rat antigen-presenting lectin-like receptor complex. Arthritis Rheum 2008, 58:1343-1353

60. Brenner M, Meng H-C, Yarlett NC, Joe B, Griffiths MM, Remmers EF, Wilder RL, Gulko PS: The non-MHC quantitative trait locus Cia5 contains three major arthritis genes that differentially regulate disease severity, pannus formation, and joint damage in collagen- and pristane-induced arthritis. J Immunol 2005, 174:7894-7903.

61. Hultqvist M, Sareila O, Vilhardt F, Norin U, Olsson LM, Olofsson P, Hellman U, Holmdahl R: Positioning of a polymorphic quantitative trait nucleotide in the Ncf1 gene controlling oxidative burst response and arthritis severity in rats. Antioxid Redox Signal 2011, 14:2373-2383.

62. International Multiple Sclerosis Genetics Consortium, Wellcome Trust Case Control Consortium 2, Sawcer S, Hellenthal G, Pirinen M, Spencer CCA Patsopoulos NA, Moutsianas L, Dilthey A, Su Z, Freeman C, Hunt SE, Edkins S, Gray E, Booth DR, Potter SC, Goris A, Band G, Bang Oturai A, Strange A, Saarela J, Bellenguez C, Fontaine B, Gillman M, Hemmer B, Gwilliam R, Zipp F, Jayakumar A, Martin R, Leslie S, Hawkins S, Giannoulatou E: Genetic risk and a primary role for cell-mediated immune mechanisms in multiple sclerosis. Nature 2011, 476:214-219.

63. Li H, Handsaker B, Wysoker A, Fennell T, Ruan J, Homer N, Marth G, Abecasis G, Durbin R, and 1000 Genome Project Data Processing Subgroup: The Sequence alignment/map (SAM) format and SAMtools. Bioinformatics 2009, 25:2078-2079.

64. McLaren W, Pritchard B, Rios D, Chen Y, Flicek P, Cunningham F: Deriving the consequences of genomic variants with the Ensembl API and SNP Effect Predictor. Bioinformatics 2010, 26:2069-2070.

doi:10.1186/1471-2164-15-391

Cite this article as: Bäckdahl et al.: Identification of candidate risk gene variations by whole-genome sequence analysis of four rat strains commonly used in inflammation research. BMC Genomics 2014 15:391.

\section{Submit your next manuscript to BioMed Central and take full advantage of:}

- Convenient online submission

- Thorough peer review

- No space constraints or color figure charges

- Immediate publication on acceptance

- Inclusion in PubMed, CAS, Scopus and Google Scholar

- Research which is freely available for redistribution

Submit your manuscript at www.biomedcentral.com/submit
C) Biomed Central 